In press at Current Opinion in Psychology.

This paper is not the copy of record and may not exactly replicate the final,

authoritative version of the article.

Prosocial behavior and altruism: A review of concepts and definitions

\author{
Stefan Pfattheicher ${ }^{1 *}$, Yngwie Asbjørn Nielsen ${ }^{1 *}, \&$ Isabel Thielmann ${ }^{2}$ \\ ${ }^{1}$ Aarhus University, Denmark; ${ }^{2}$ University of Koblenz-Landau, Germany \\ * These authors contributed equally to the work
}

Corresponding author:

Stefan Pfattheicher

Aarhus University

Department of Psychology and Behavioral Sciences

8000 Aarhus C, Denmark

sp@psy.au.dk 


\begin{abstract}
The field of prosociality is flourishing, yet researchers disagree about how to define prosocial behavior and often neglect defining it altogether. In this review, we provide an overview about the breadth of definitions of prosocial behavior and the related concept of altruism. Common to almost all definitions is an emphasis on the promotion of welfare in agents other than the actor. However, definitions of the two concepts differ in terms of whether they emphasize intentions and motives, costs and benefits, and the societal context. In order to improve on the conceptual ambiguity surrounding the study of prosociality, we urge researchers to provide definitions, to use operationalizations that match their definitions, and to acknowledge the diversity of prosocial behavior.
\end{abstract}

Keywords: Prosocial behavior; altruism; definition; conceptualization; review 


\section{Prosocial behavior and altruism: A review of concepts and definitions}

Progress is often hindered by poor communication between scientists, with different people using the same term to mean different things, or different terms to mean the same thing. [...] The potential for such semantic confusion is greatest with interdisciplinary research.

—West et al. [1, p. 415]

Prosocial behavior is a wonderful thing. People help strangers they will never meet again, they donate time and valuables to charity, and they care intensively for their friends and family. Corresponding to this ubiquity, the study of prosocial behavior has received remarkable attention over the past decades (see Figure 1). In some sense, the current state of research on prosocial behavior resembles a field of wild flowers: On the one hand, it carries a beautiful diversity in form and expression. On the other hand, the field is disordered, wild, and untamed.

In fact, in its current state, the field of prosocial behavior is plagued by conceptual ambiguity. As early as in 1984, Dovidio stated, "despite (or perhaps because of) the impressive amount of research that has focused on prosocial, helping, and altruistic behaviors, there is little consensus concerning how these terms should be defined or distinguished from one another" [2*, p. 363]. Almost 40 years later, disagreements and confusion about how to define prosocial behavior, and the closely related concept of altruism, are still an actuality. ${ }^{1}$

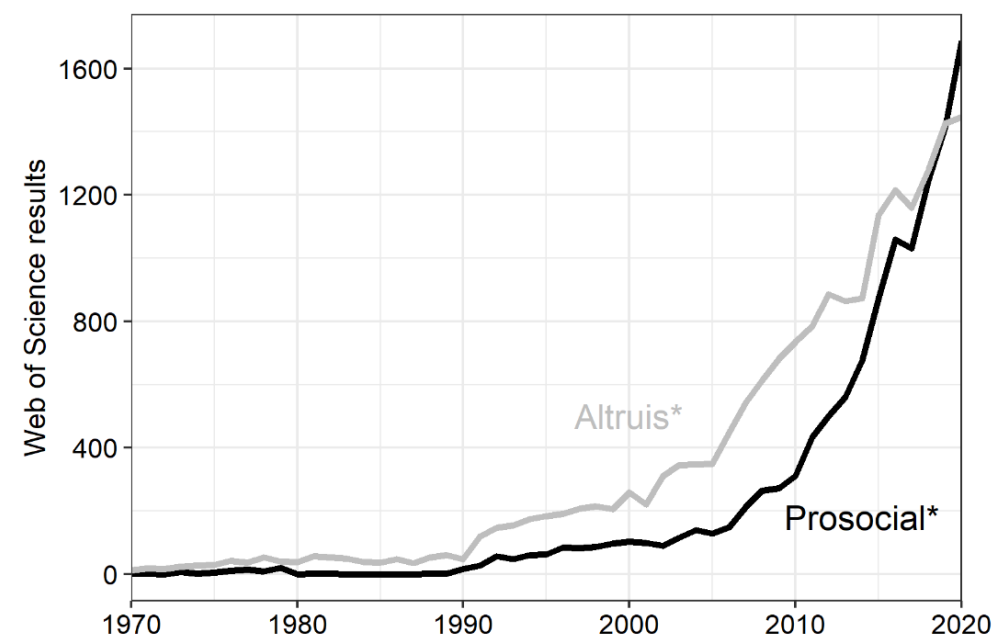

Figure 1. Number of publications since 1970 that include prosocial* (e.g., prosocial behavior, prosocial lies) or altruis* (e.g., altruism, altruistic behavior) in their title, abstract, or keywords; data was collected from Web of Science in June 2021.

\footnotetext{
${ }^{1}$ A complete conceptual disentanglement would require us to also consider related constructs, such as cooperation and helping $\left[3,4^{*}, 5\right]$. In the present paper, we start this conceptual journey by providing an overview about the breadth of definitions of prosocial behavior and altruism, while hoping that future research may follow up on this and extend it to other related concepts in the realm of prosociality.
} 
Adding to the significant conceptual ambiguity in the field, researchers often miss out on providing definitions of the key terms used in their articles. We assessed the prevalence of definitions of prosocial behavior and altruism in all articles including the terms prosocial* (e.g., prosocial behavior, prosocial lies) or altruis* (e.g., altruism, altruistic behavior) in the title, abstract, or keywords that were published between January 2010 and May 2021 in Journal of Personality and Social Psychology $(n=81)$, Journal of Experimental Social Psychology $(n$ =68), Personality and Social Psychology Bulletin $(n=53)$, and Psychological Science $(n=$ 71). Strikingly, only 70 out of 273 (25.6\%) articles included a relevant definition (the extracted list of definitions can be found at https://osf.io/6nh25). ${ }^{2}$ In other words, only about a fourth of the identified articles defined their concept of central interest. Given the conceptual issues associated with such practice, our analysis clearly shows that we need to enforce the use of definitions more.

In this review, we identify key dimensions that distinguish and characterize different conceptualizations of prosocial behavior in the extant literature. We also include the term altruism in our analysis given that this concept has close conceptual ties with prosocial behavior but needs to be distinguished from it [2*]. Thus, we specify in which respects different definitions of prosocial behavior and altruism agree and - more crucially — disagree. Based on this analysis, we provide three recommendations for future research to reduce conceptual ambiguity when studying the two concepts.

\section{Definitions and dimensions of prosocial behavior and altruism}

Based on the list of definitions we extracted from the journal articles mentioned above as well as from previous reviews (e.g., $\left[5,6^{* *}, 7^{* *}\right]$ ), we identified a common core and three key dimensions that distinguish and characterize different conceptualizations of prosocial behavior and altruism: (i) intentions and motives, (ii) costs and benefits, and (iii) societal context (see Table 1). Before going into detail, we want to emphasize that our analysis is descriptive rather than normative, that is, we do not designate one "correct" way of conceptualizing and defining prosocial behavior and altruism. Each of the reviewed definition has its own raison d'être, and hence we do not propose a new definition ourselves. Instead, we describe how the terms are currently being used in the literature.

\footnotetext{
${ }^{2} \mathrm{~A}$ fifth of the articles were independently re-coded, yielding adequate inter-rater reliability of $\kappa=.73$ with $89 \%$ consensus. Details on method and analysis can be found at https://osf.io/6nh25/.
} 
Common to almost all definitions is that prosocial and altruistic behaviors reflect acts of "positive" social behavior towards one or several others $\left[5,6^{* *}, 8\right]$. Most often-but not necessarily (e.g., $\left[2^{*}\right]$ ) — these acts are described as promoting or being intended to promote the welfare of others $[5,8] .^{3}$

Two points are worth emphasizing here. First, definitions differ with regard to who the receiver of welfare is, varying from one or several individuals to groups or even society at large $[3,5]$. In turn, some scholars require prosocial behavior to be interpersonal [5], whereas other definitions include non-human entities (e.g., animals) as potential recipients [10]. Second, the meaning of "welfare" varies greatly across fields, including (evolutionary) fitness benefits [1], psychological well-being [6**], and resources or utility, respectively (e.g., money [11]).

\subsection{Intentions and motives}

Multiple definitions stress the intentional nature of prosocial behavior. For instance, Batson and Powell [12, p. 463, emphasis added] state that "prosocial behavior covers the broad range of actions intended to benefit one or more people other than oneself' (see also $[9,13])$.

According to this conceptualization, the intention to generate welfare in others suffices for a behavior to be considered prosocial. This notion highlights the decisive difference between defining prosocial behavior based on intention as opposed to (welfare-promoting) consequences. For example, privately praying for another's good health involves the intention to promote the other's welfare and would thus be considered prosocial from an intentionalist perspective, although it will probably not increase the other's welfare. Similarly, actions that are pursued in good faith but that have unintended adverse consequences (e.g., "helicopter parenting") are also considered prosocial according to an intentionalist perspective. In essence, all behaviors that the actor considers as being prosocial (consciously or not) count as such, irrespective of the actual consequences produced.

\subsubsection{Altruism from an intentionalist perspective}

Some researchers define altruism as a specific motivational state often related to prosocial behavior, for which actual consequences play a negligible role. For example, Batson [14**, p. 16] defines altruism as "motivation with the ultimate goal of increasing another's welfare" (see also $[12,15])$. In a similar but distinct approach, altruism has been considered as a subtype of

\footnotetext{
${ }^{3}$ Many definitions require that prosocial behavior is volitional (or non-accidental). Sometimes this is done explicitly (e.g., [9]), other times, it is implied by the word "act." In the interest of brevity and due to the volatility of the concept volition, we forego this discussion.
} 
(intentional) prosocial behavior with a specific underlying motivation. For example, Eisenberg and Miller [9, p. 92] define altruism as prosocial behavior "which is not performed with the expectation of receiving external rewards or avoiding externally produced aversive stimuli or punishments" (see also [16-18]). According to the intentionalist perspective, prosocial behavior and altruism are distinct but complementary concepts; whereas prosocial behavior refers to the mere action itself, altruism additionally refers to why that action is taken. In other words, whereas altruism pursues the ultimate goal of increasing another's welfare [14**], prosocial behavior reflects a broader category of welfare-promoting acts that may be based on multiple motives, including altruistic, egoistic, or unspecified ones [9,19] (see also [18]).

Consider the example of a promotion-seeking employee complimenting their superior as a means of ingratiation. This action has prosocial intentions (i.e., to make the superior feel good), but is at the same time egoistically motivated because the ultimate goal of the employee is to increase their own welfare (i.e., promotion). Thus, the behavior would be considered prosocial according to an intentionalist perspective, but not altruistic. By definition, altruistic behavior is executed with the ultimate goal of promoting welfare in others as an end in and of itself and not to obtain personal benefits. This reasoning does not, however, prevent that altruistic behavior can benefit the acting individual through unintended consequences (e.g., one can feel better after the act $\left.\left[14^{* *}\right]\right)$.

\subsection{Costs and benefits}

Some definitions of prosocial behavior stress the consequences of the behavior more so than the underlying intentions and motives. For example, Schroeder and Graziano [5, p. 255] define prosocial behavior broadly as "any action that benefits another" (see also $[3,8]$ ). From such a consequentialist perspective, what matters is that the behavior causes welfare in others, whether intended or not. Thus, privately praying for another's good health would not be considered as prosocial behavior per se but ingratiating your superior would. In essence, the consequentialist

logic does not consider a behavior as being prosocial unless the behavior has positive consequences for another.

\subsubsection{Altruism from a consequentialist perspective}

According to a consequentialist perspective, altruism refers to a behavior with costs for the actor and benefits for the receiver $\left[7^{* *}, 20\right]$. As opposed to intentionalist definitions, researchers employing a consequentialist perspective rarely distinguish between altruism and prosocial 
behavior. However, what is emphasized from a consequentialist perspective is that altruistic behavior is costly.

How costs and benefits are calculated differs across research traditions, most prominently between an economic (i.e., resource-oriented) approach and an evolutionary approach. This, in turn, hinders generalizations across these disciplines because different conceptualizations of costs are studied $\left[7^{* *}\right]$. From an economic approach, altruistic behaviors are "costly acts that confer economic benefits on other individuals" [11, p. 785]. Costs (and benefits) are often conceptualized as giving away money (e.g., in the social value orientation literature [21]), but sometimes also include other resources such as time or energy [22]. From an evolutionary approach, altruism reflects "a behavior that is costly to the actor and beneficial to the recipient(s). Costs and benefits are defined on the basis of the lifetime direct fitness" [23**, p. 232] (see also [15,24,25]). Unlike in the economic approach, costs and benefits are not calculated within a short timeframe (e.g., within a given situation); rather, the behavior, repeatedly shown across different situations over an individual's lifetime, is costly if and only if it reduces an individual's number of offspring that survive to adulthood [23**].

Emphasizing costs in the consequentialist perspective seems remarkably different from the intentionalist definitions of altruism reviewed above. However, since both costs and "ultimate goals of benefitting another" are incongruent with egoism, both approaches seemingly manage to exclude egoistically driven prosocial behavior, although in strikingly different ways.

\subsection{Societal context}

There is a third approach to defining prosocial behavior beyond focusing on intentions and consequences. From this societal perspective, prosocial behavior means "no more, and no less, than behavior that is valued by the individual's society" [2*, p. 364] (see also [4*]). Thus, the key feature of prosocial behavior is societal approval.

Unlike the intentionalist and consequentialist perspectives, this societal perspective does not explicitly require a behavior to (be intended to) promote others' welfare; what matters is the approval by others, rendering prosocial behavior an inherently normative phenomenon. This conceptualization thus includes behaviors such as donating to charity or privately praying for another's good health if and only if these behaviors are valued by society. Thus, a societal perspective may potentially allow behavior that ultimately decreases others' welfare into the ranks of prosocial behavior, such as militant actions that harm another group (and only indirectly contribute to one's own group's welfare, if at all [2*]). 


\subsubsection{Altruism from a societal perspective}

Of the reviewed perspectives, a societal approach seems to come closest to the original meaning of altruism. When Auguste Comte coined the term, altruism referred to the collectivistic principle of living one's life for others - the opposite of egoism [26]. Likewise, Bykov [27**, p. 808] defines altruism as "a moral norm [which] implies certain social expectations of helping others in different social contexts". ${ }^{4}$ This definition implies that altruism reflects more than the ultimate goal of benefitting others and foregoing personal gains. Instead, altruism reflects societal expectations and a guiding principle of how to behave in society: One abstains from personal profits to benefit the collective [27**,28]. Thus, whereas prosocial behavior from a societal perspective refers to behavior that is valued and expected by society [2*], altruism is more specific in that what is valued and expected is clearly defined, namely promoting the welfare of the collective.

\section{Recommendations}

Definitions are important. Without them, researchers risk using the same term for different concepts, and different terms for the same concept (known as the jingle and jangle fallacies [29]). When used appropriately, definitions improve interdisciplinary communication and, thereby, foster cumulative science-which is especially important when researchers from different disciplines work on the same puzzling phenomena, such as prosocial behavior or altruism $\left[1,7^{* *}, 27^{* *}\right]$. Here, we provided an overview of the key dimensions on which definitions of prosocial behavior and altruism differ. ${ }^{5}$ In what follows, we derive three recommendations for researchers: (i) define your terms; (ii) use operationalizations that match your definition(s); and (iii) acknowledge the diversity of prosocial behavior.

As shown by our literature search, more than $74 \%$ of articles on prosocial behavior and altruism published in prominent (social) psychological journals lack definitions of their key constructs. Thus, our first recommendation for future research is straightforward: define the constructs under scrutiny. Table 1 provides an exemplary collection of definitions that capture the different dimensions and perspectives in the literature (the table, however, misses out on some definitions that combine different dimensions, notably [30*]). Researchers should select the definition(s) that match their conceptualization best, and then be explicit about how they

\footnotetext{
${ }^{4}$ We abstain from the discussion of what morality is and what social and moral norms are. As is often the challenge with conceptual work, defining one term requires the invocation of another term in equal need of clarification (e.g., costs, intention, or welfare)

${ }^{5}$ We want to acknowledge that our review is non-comprehensive, and that we might have missed out some definitions and key dimensions used in other disciplines.
} 
understand these definitions. This is particularly important given that what constitutes, for example, "costs" or "welfare" may differ across disciplines, but also across cultures and societies [31]. Importantly, in order to promote a common language across fields, researchers should strive to apply existing definitions, rather than tailoring their definition to the theory, study, or psychological processes under investigation.

Second, operationalizations should match one's definition (see $\left[6^{* *}, 7^{* *}, 30^{*}\right]$ ). In fact, the way a concept is measured should naturally follow from how it is defined. For example, if prosocial behavior is defined as intentional, the paradigm used to assess prosocial behavior must measure intentions.

Third, researchers should acknowledge the diversity of prosocial behavior (and altruism) inherent in extant conceptualizations. Clearly, the term "prosocial behavior" is very broad and used to refer to a variety of different concepts, which may obscure meaningful differences in the actual phenomena under scrutiny. Thus, researchers studying one manifestation of prosocial behavior (e.g., donations to charity, helping a friend) should not assume that their findings will automatically generalize to other manifestations of prosocial behavior. Instead, the huge variety of prosocial behaviors should be acknowledged in order to recognize the specificity of one's findings.

\section{Concluding remarks}

Together with many other researchers, we share the excitement about the study of prosocial behavior. To more strongly connect (abstract) theory and (concrete) behavior we need to carefully define and operationalize our constructs. More conceptual work is needed to clearly distinguish prosocial behavior from altruism and other types of prosocial behavior (such as cooperation and helping), and we should take care to avoid using the terms interchangeably. We hope that the present paper will encourage scholars targeting prosocial behavior or altruism in their research to use definitions more often and mindfully - to further develop the exciting field of prosocial behavior. 
Table 1. Exemplary definitions of prosocial behavior and altruism.

\begin{tabular}{|c|c|c|c|}
\hline Concept and dimension & Exemplary definition & Reference & \\
\hline $\begin{array}{l}\text { Prosocial behavior } \\
\text { emphasizing intentions }\end{array}$ & $\begin{array}{l}\text { "Prosocial behavior covers the broad range of actions } \\
\text { intended to benefit one or more people other than oneself" }\end{array}$ & Batson \& Powell (2003, p. 463) & {$[12]$} \\
\hline $\begin{array}{l}\text { Prosocial behavior } \\
\text { emphasizing consequences }\end{array}$ & "any action that benefits another" & Schroeder \& Graziano $(2015$, p. 255$)$ & {$[5]$} \\
\hline $\begin{array}{l}\text { Prosocial behavior emphasizing } \\
\text { intentions and consequences }\end{array}$ & $\begin{array}{l}\text { "voluntary, intentional behavior that results in benefits for } \\
\text { another" }\end{array}$ & Eisenberg and Miller (1987, p. 92) & {$[9]$} \\
\hline $\begin{array}{l}\text { Prosocial behavior } \\
\text { emphasizing societal context }\end{array}$ & $\begin{array}{l}\text { "prosocial behavior means no more, and no less, than } \\
\text { behavior that is valued by the individual's society" }\end{array}$ & Dovidio (1984, p. 364) & {$[2 *]$} \\
\hline $\begin{array}{l}\text { Prosocial behavior } \\
\text { emphasizing societal context and } \\
\text { consequences }\end{array}$ & $\begin{array}{l}\text { "Prosocial behavior represents a broad category of acts that } \\
\text { are defined by some significant segment of society and/or } \\
\text { one's social group as generally beneficial to other people" }\end{array}$ & Penner et al. $(2005$, p. 366$)$ & {$[4 *]$} \\
\hline $\begin{array}{l}\text { Altruistic motivation from an } \\
\text { intentionalist perspective }\end{array}$ & $\begin{array}{l}\text { "motivation with the ultimate goal of increasing another's } \\
\text { welfare" }\end{array}$ & Batson et al. (2010, p. 16) & {$\left[14^{* *}\right]$} \\
\hline $\begin{array}{l}\text { Altruistic behavior from an } \\
\text { intentionalist perspective }\end{array}$ & $\begin{array}{l}\text { "voluntary behavior intended to benefit another, which is not } \\
\text { performed with the expectation of receiving external rewards } \\
\text { or avoiding externally produced aversive stimuli or } \\
\text { punishments" }\end{array}$ & Eisenberg \& Miller (1987, p. 92) & [9] \\
\hline $\begin{array}{l}\text { Altruism from a consequentialist } \\
\text { perspective (emphasizing economic } \\
\text { costs and consequences) }\end{array}$ & $\begin{array}{l}\text { "costly acts that confer economic benefits on other } \\
\text { individuals" }\end{array}$ & Fehr \& Fischbacher (2003, p. 785) & {$[11]$} \\
\hline $\begin{array}{l}\text { Altruism from a consequentialist } \\
\text { perspective (emphasizing evolutionary } \\
\text { costs and consequences) }\end{array}$ & $\begin{array}{l}\text { "A behavior that is costly to the actor and beneficial to the } \\
\text { recipient or recipients. Costs and benefits are defined on the } \\
\text { basis of the lifetime direct fitness consequences of a behavior" }\end{array}$ & West et al. (2011, p. 232) & {$[23 * *]$} \\
\hline Altruism from a societal perspective & $\begin{array}{l}\text { "a moral norm [which] implies certain social expectations of } \\
\text { helping others in different social contexts" }\end{array}$ & Bykov $(2017$, p. 808) & {$[27 * *]$} \\
\hline
\end{tabular}




\section{References}

(*) of special interest

(**) of outstanding interest

[1] S.A. West, A.S. Griffin, A. Gardner, Social semantics: Altruism, cooperation, mutualism, strong reciprocity and group selection, J. Evol. Biol. 20 (2007) 415-432. https://doi.org/10.1111/j.1420-9101.2006.01258.x.

[2] J.F. Dovidio, Helping behavior and altruism: An empirical and conceptual overview, in: L. Berkowitz (Ed.), Adv. Exp. Soc. Psychol., Academic Press, 1984: pp. 361-427. https://doi.org/10.1016/S0065-2601(08)60123-9.

* In this chapter, prosocial behavior, helping behavior, and altruism are briefly delineated, and four dimensions of altruism (consequences, locus of reinforcement, intentions, and motivation) are identified.

[3] M. Snyder, P.C. Dwyer, Altruism and prosocial behavior, in: Handb. Psychol. Personal. Soc. Psychol. Vol 5 2nd Ed, John Wiley \& Sons, Inc., Hoboken, NJ, US, 2013: pp. 467-485.

[4] L.A. Penner., J.F. Dovidio., J.A. Piliavin., D.A. Schroeder., Prosocial behavior: Multilevel perspectives, Annu. Rev. Psychol. 56 (2005) 365-392. https://doi.org/10.1146/annurev.psych.56.091103.070141.

* It is argued that the literature on prosocial behavior can be organized and understood from a multilevel perspective, including the micro-level (focusing on the origins of prosocial tendencies and its individual variations), the meso-level (focusing on dyads in different contexts), and the macro-level (focusing on prosocial behavior in the context of groups and organizations).

[5] D.A. Schroeder, W.G. Graziano, The field of prosocial behavior, in: D.A. Schroeder, W.G. Graziano (Eds.), Oxf. Handb. Prosocial Behav., Oxford University Press, 2015. https://doi.org/10.1093/oxfordhb/9780195399813.013.32.

[6] L.G. Wispé, Positive forms of social behavior: An overview, J. Soc. Issues. 28 (1972) 1-19. https://doi.org/10.1111/j.1540-4560.1972.tb00029.x.

** This early review covers various conceptualizations of prosocial behavior (including aid, donation, cooperation, helping, altruism, and sympathy) and highlights the issue of correspondence between concepts and measures of prosocial behavior.

[7] C. Clavien, M. Chapuisat, Altruism across disciplines: One word, multiple meanings, Biol. Philos. 28 (2013) 125-140. https://doi.org/10.1007/s10539-012-9317-3.

** This article distinguishes four types of altruism: psychological (i.e., intentionalist) altruism, reproductive (i.e., evolutionary and consequentialist) altruism, behavioral (i.e., consequentialist) altruism, and preference altruism (denoting a repeated exhibition of costly prosocial behavior). In addition, the authors highlight ambiguity in the extant literature and the issues inherent in generalizing findings across different types of altruism. 
[8] E. Staub, Positive social behavior and morality, Academic Press, 1978. https://doi.org/10.1016/C2013-0-11528-0.

[9] N. Eisenberg, P. Miller, The relation of empathy to prosocial and related behaviors, Psychol. Bull. 101 (1987) 91-119. https://doi.org/10.1037/0033-2909.101.1.91.

[10] K.A. Cronin, Prosocial behaviour in animals: The influence of social relationships, communication and rewards, Anim. Behav. 84 (2012) 1085-1093. https://doi.org/10.1016/j.anbehav.2012.08.009.

[11] E. Fehr, U. Fischbacher, The nature of human altruism, Nature. 425 (2003) 785-791. https://doi.org/10.1038/nature02043.

[12] C.D. Batson, A.A. Powell, Altruism and prosocial behavior, in: T. Millon, M.J. Lerner, I.B. Weiner (Eds.), Handb. Psychol., John Wiley \& Sons, 2003: pp. 463-484. https://doi.org/10.1002/0471264385.wei0519.

[13] J. Zaki, J.P. Mitchell, Intuitive prosociality, Curr. Dir. Psychol. Sci. 22 (2013) 466-470. https://doi.org/10.1177/0963721413492764.

[14] C.D. Batson, Empathy-induced altruistic motivation, in: M. Mikulincer, P.R. Shaver (Eds.), Prosocial Motiv. Emot. Behav. Better Angels Our Nat., American Psychological Association, Washington, D.C., USA, 2010: pp. 15-34. https://doi.org/10.1037/12061001.

** An intentionalist perspective is taken in this chapter. The argument is put forward that altruism is best understood and studies as a motivational state. It is concluded that "true" altruism does exists and emerges in situations when one feels empathy for another person.

[15] E. Sober, D.S. Wilson, Unto others: The evolution and psychology of unselfish behavior, Harvard University Press, Cambridge, 1998.

[16] J. Macaulay, L. Berkowitz, Altruism and helping behavior: Social psychological studies of some antecedents and consequences., Academic Press, New York, 1970.

[17] M.L. Hoffman, Is altruism part of human nature?, J. Pers. Soc. Psychol. 40 (1981) 121137. https://doi.org/10.1037/0022-3514.40.1.121.

[18] D.L. Krebs, Altruism and egoism: A false dichotomy?, Psychol. Inq. 2 (1991) 137-139. https://doi.org/10.1207/s15327965pli0202_9.

[19] E.G. Clary, M. Snyder, R.D. Ridge, J. Copeland, A.A. Stukas, J. Haugen, P. Miene, Understanding and assessing the motivations of volunteers: A functional approach, J. Pers. Soc. Psychol. 74 (1998) 1516-1530. https://doi.org/10.1037/00223514.74.6.1516.

[20] M. Tomasello, Why we cooperate, MIT Press, Cambridge, MA, USA, 2009.

[21] R.O. Murphy, K.A. Ackermann, Social value orientation: Theoretical and measurement issues in the study of social preferences, Personal. Soc. Psychol. Rev. 18 (2014) 13-41. https://doi.org/10.1177/1088868313501745. 
[22] B. Latané, J.M. Darley, The unresponsive bystander: Why doesn't he help?, AppletonCentury Crofts, New York, 1970.

[23] S.A. West, C. El Mouden, A. Gardner, Sixteen common misconceptions about the evolution of cooperation in humans, Evol. Hum. Behav. 32 (2011) 231-262. https://doi.org/10.1016/j.evolhumbehav.2010.08.001.

** Taking an evolutionary perspective, this paper clarifies misconceptions of commonly used terms including "altruism," "cooperation," and "selfishness."

[24] R.L. Trivers, The evolution of reciprocal altruism, Q. Rev. Biol. 46 (1971) 35-57. https://doi.org/10.1086/406755.

[25] G. Piccinini, A.W. Schulz, The ways of altruism, Evol. Psychol. Sci. 5 (2019) 58-70. https://doi.org/10.1007/s40806-018-0167-3.

[26] A. Comte, System of positive polity, Longmans, Green, and Co., London, 1875.

[27] A. Bykov, Altruism: New perspectives of research on a classical theme in sociology of morality, Curr. Sociol. 65 (2017) 797-813. https://doi.org/10.1177/0011392116657861.

** This paper gives an overview about the term altruism, mainly from a societal perspective. It is outlined where the term "altruism" comes from, and how sociologists have applied the term throughout history until today.

[28] E. Durkheim, The division of labor in society, The Free Press, 1997.

[29] J. Block, A contrarian view of the five-factor approach to personality description, Psychol. Bull. 117 (1995) 187-215. https://doi.org/10.1037/0033-2909.117.2.187.

[30] D. Bar-Tal, Altruistic motivation to help: Definition, utility and operationalization, Humboldt J. Soc. Relat. 13 (1986) 3-14.

* This article proposes a five-part definition of altruism including (a) benefits to another, (b) volition, (c) intention, (d) benefit as an ultimate goal, and (e) a lack of external incentives. Crucially, the authors discuss the kind of operationalization necessary to match the content of their definition.

[31] J. Henrich, S.J. Heine, A. Norenzayan, The weirdest people in the world?, Behav. Brain Sci. 33 (2010) 61-83. https://doi.org/10.1017/S0140525X0999152X. 